Ivan V. Leonov, Dr. of Cultural Studies, Sankt Petersburg State Institute of Culture, The Anna Akhmatova Literary and Memorial Museum in Fountain House

(Saint Petersburg, Russia) ivaleon@mail.ru

\title{
REPRESENTATION OF TRADITIONAL CULTURES IN SOUVENIR INDUSTRY
}

\begin{abstract}
The article analyses the current state and the key directions of development of the modern Russian industry of ethnic, historical, and cultural souvenirs. The phenomenon of dependence between a range of souvenir products and strength of stereotypes in cultural consciousness towards the historical and today's Russia, its historical and cultural zones. The author discloses an effect of influence of artistic and aesthetic image of souvenir products on buyers' views on cultural peculiarities of peoples of the today's Russia, touches an issue about permissible limits of falsification of Russian historical and cultural reality that appears because of low-quality souvenir products in market.

Keywords: a souvenir, an artefact, fields of culture, historical and cultural process, a visual image, humanitarian technologies, representation of a traditional culture, historical and cultural representativeness of a souvenir.
\end{abstract}

\section{References}

1. Benjamin, V. Proizvedenie iskusstva v epohu ego tekhnicheskoj vosproizvodimosti. Izbrannye esse [The Work of Art in the Age of Mechanical Reproduction] Moscow, 1996. 240 c. [In Russ.].

2. Berger, J. Iskusstvo videt' [Ways of Seeing].Saint Petersburg, 2012. 184 c. [In Russ.]

3. Mahlina S. T. Palekh vchera i segodnya [Palekh Miniature Yesterday and Tomorrow] //
Peterburgskie iskusstvovedcheskie tetrad [Petersburg Notebooks in Art of Criticism]. Saint Petersburg, 2017. Is. 43. Pp. 70-85. [In Russ.].

4. Thagapsoev, H. G. Identichnost' kak navigator soznaniya [Identity as a Way Finder for Consciousness] / H. G. Thagapsoev, L. M. Mosolova, I. V. Leonov, V. L. Solov'yova. Saint Petersburg, 2016. 170 p. [In Russ.].

УДК 82-131(470.55)=512.1

DOI: $10.32340 / 2514-772 X-2019-1-87-96$

Л. Х. Мухаметзянова, доктор философских наук, доцент Институт языка, литературы и искусства им. Г. Ибрагимова Академии наук Республики Татарстан (Казань, Россия) lilmuhat@mail.ru

\section{МЕЖДУ ВОЛГОЙ И УРАЛОМ: ЭПИЧЕСКИЕ ЦЕННОСТИ ТАТАР И БАШКИР, ПРОЖИВАЮЩИХ В ЧЕЛЯБИНСКОЙ ОБЛАСТИ РОССИЙСКОЙ ФЕДЕРАЦИИ}

Аннотация. Раскрыто содержание наиболее популярных сюжетных конструкций дастанов эпических произведений татарского и башкирского народного творчества; проанализированы некоторые сюжетные особенности известных дастанов. Отмечена связь между миграцией части татарского и башкирского этносов в сибирский регион и жанровыми трансформациями дастанов. Представлены фрагменты нотных записей достанов «Йосыф китабыl», «Сайфульмулюк», «Буз егет» и др. Охарактеризованы направления работы Институт языка, литературы и искусства им. Г. Ибрагимова Академии наук Республики Татарстан (г. Казань, Россия) в области сбора, научного анализа и популяризации образцов дастанов.

Ключевые слова: фольклор тюркских народов России, татарский фольклор, башкирский фольклор, татарский эпос, башкирский эпос, дастан, сюжет достана, фольклорная экспедиция, Институт языка, литературы и искусства им. Г. Ибрагимова Академии наук Республики Татарстан.

Дастан - эпический жанр в татарском и башкирском народном творчестве, эквивалентный понятию эпос в фольклористике. В начальной стадии своего развития дастаны передавались устно сэсэнами или чичянами- импровизаторами. Эти произведения пользовались большой популярностью; кочуя из столетия в столетие, из поколения в поколение, они практически сохранились в своем первозданном виде. Эпос татар и башкир уходит 
корнями в древнейшие формы фольклора, в мифологию, стремящую воспроизвести легендарную предысторию этноса и мира в целом.

В современном татарском и башкирском фольклоре наблюдается процесс исчезновения полноценного исполнения дастана, как объёмного эпического произведения. Сегодня во время экспедиций в регионах компактного проживания татар или башкир для фольклориста большая редкость услышать из уст информанта фрагмент из дастана или эпическую песнь в живом исполнении. Эпос-дастаны, бытовавшие когда-то в репертуаре сказителя, имеют стремительную тенденцию к угасанию. Изучение локальных этнокультурных явлений важно при выявлении единого культурного целого, взятого в общетюркском культурном контексте. В процессе фольклорных экспедиций в регионах компактного проживания татар, в том числе и в Челябинской области, были записаны образцы эпической поэзии. Информанты Челябинской области испокон веков вносят огромный вклад в дело сохранения фольклора. Академические тома по башкирскому (1954-1959, 1972-1985, 1987-2010, 1990-2018) и татарскому (197...1988) народному творчеству изобилуют записанными из уст информантов данного региона или сданными ими в архив рукописными материалами. Ценность найденных во время экспедиций эпических материалов с каждым годом растёт, они требуют к себе тщательного внимания и скрупулёзного изучения и анализа. В наше время практически не осталось совершенно изолированных от мира культурных общностей; в этом отношении татары и башкиры не являются исключением, именно поэтому целесообразно изучение эпического творчества двух братских народов в совокупности. Челябинская область как раз и является той территорией, где прослеживается тесное и объективное взаимовлияние двух культур на уровне философии родственных взаимоотношений (близость языка, единая вера, кровное родство и т. д.).

Изучение эволюции и трансформации фольклорно-археографических материалов с учётом не только историко-культурного опыта этноса, но и результатов общения разных культур, в свою очередь, позволяет приблизиться к постижению своеобразия и общечеловеческого в мышлении народа. Расселённые дисперсно по разным регионам России и за её пределы татары живут в тесном контакте с другими родственными и неродственными народами. У этих народов много общего и сближающего в их традициях и обычаях.

Самые ранние сведения о татарах, прожи- вающих в Челябинской области, относятся к XI в. Персидский учёный ал-Гардизи пишет о вхождении территорий Южного Урала, в том числе земель сегодняшней Челябинской области, в средневековое тюркское Кимакское государство. Оно объединяло семь родственных племён, среди которых были племена с названиями Татары и Кипчаки. Татары жили в западной части каганата, где ныне расположена Челябинская область, и имели статус управленцев [1]. Историк XIV в. Ибн Халдун также упоминает о татарах, которые образовали отдельную этногенетическую ветвь [1].

В период формирования этносов нынешняя Челябинская область была под властью Золотой Орды. На этих землях тюрки продолжали свой род. В золотоордынскую эпоху через южную часть Челябинской области проходил караванный торговый путь. Народы, проживающие в Южном Урале, в том числе татары и башкиры, ещё с XIII в. принимали активное участие в торгово-экономической жизни края, строили городища, крепости. Отголосками далёкой тюркской истории Челябинской области служат найденные за последние годы археологами древние городища, мавзолеи. Например, Тамерланская башня по своей архитектуре, использованным в её строительстве материалам (знаменитый «татарский кирпич» квадратной формы) олицетворяет из себя образец материальной культуры средневековых тюрков и т. д.

После распада Золотой Орды территории северной части нынешней Челябинской области вошли в состав Сибирского ханства, южная часть отошла к Ногайской Орде [2, с. 62]. Эти земли стали пристанищем татар и башкир после завоевания Казанского ханства в 1552 г. русским государством. В XVII в. после распада Сибирского ханства территория Челябинской области, где жили и работали служилые татары и башкиры, отошла к русским землям. С этого периода здесь строились новые крепости татаро-башкирских казачьих отрядов. Известны Миасская, Челябинская, Чебаркульская крепости. В их строительстве активное участие принимали именно татары и башкиры, впоследствии они использовали эти крепости в военных целях. В XIX - XX столетиях в Южный Урал устремился поток татарских и башкирских мигрантов из Оренбургской, Уфимской губерний.

Таким образом, в Челябинской области татары и башкиры имеют тысячелетнюю историю компактного проживания. Близкродственные тюркские народы, татары и башки- 
ры, здесь - коренные народы. Современные татары и башкиры, проживающие в этих землях, укомплектованы из хронологически и географически разнородных этнических групп и племён. Они образуют своеобразный пласт татароязычных и башкироязычных, конфессионально объединенных представителей двух наций, традиционные культуры которых взаимно дополняют и обогащают друг друга на протяжении многих веков.

Институт языка, литературы и искусства им. Г. Ибрагимова Академии наук Республики Татарстан с 1939 г. занимается сбором и подготовкой к изданию татарского культурного наследия. Ученые ежегодно выезжают в экспедиции по разным направлениям с целью изучения проблем межкультурного и межнационального общения татарского этноса. Их научные исследования указывают на то, что национальная культура, духовность, язык, обычаи и традиции, исторические корни являются общей кладезью для многих этнических представителей разных народов и их надо беречь.

Например, в 1978 и 1979 гг. ученые Института языка, литературы и искусства им. Г. Ибрагимова Академии наук Республики Татарстан (далее - ИЯЛИ им. Г. Ибрагимова) выехали на фольклорную экспедицию в Челябинскую область и вернулись оттуда с большим «багажом». Экспедиция 1978 года, в которой принимали участие сотрудники ИЯЛИ им. Г. Ибрагимова Котдус Хуснуллин (руководитель), Рашит Ягфаров, Асия Садикова, Камария Ямалетдинова, проводилась в Кунашакском районе Челябинской области, и охватила такие села, как Кунашак, Муслюмово, Узбагаряк. А в 1979 г. Илбарис Надиров (руководитель), Ленар Замалетдинов, Асия Садикова, Салим Гилязутдинов, Хузиахмет Махмутов, Рашит Ягфаров работали в Троицком, Октябрьском, Варновском районах. До 2000 гг. экспедиции ИЯЛИ им. Г. Ибрагимова проводились профильно. В результате общения с татароязычными информантами, фольклористами были записаны лирические и эпические песни, баиты, загадки, предания, мифологические рассказы, новые варианты дастанов на ранее известные сюжеты, сказки и др. Отобранные образцы прошлых экспедиций в Челябинскую область вошли в фольклорные сборники, а расшифрованные рукописи хранятся в Центре письменного и музыкального наследия ИЯЛИ им. Г. Ибрагимова [16].

Эпос татар Челябинской области интересен тем, что в нем сохранились устные вариан- ты некоторых дастанов, в то время как у поволжских татар они трансформировались в книжную разновидность, либо же, перешагнув жанровые границы, превратились, например, в сказки. В бескрайних сибирских просторах с легкостью осуществлялось основное условие для развития нематериальной и материальной культуры - в регионе с давних времен сохранилась относительная политическая и экономическая стабильность, отсутствие кардинальных изменений в жизни народа создавало благоприятные условия для развития традиционной духовной культуры. Этим можно объяснить сохранность многих объемных эпосдастанов у татар, проживающих в Сибири. Перекочевавшие из Поволжья в Сибирь образцы эпических жанров фольклора здесь приобрели новую жизнь, вновь участвуя в актуализации фольклора. Географическая близость с Сибирью и кровное родство населения Южного Урала повлияли на быстрое распространение в этой местности эпических сюжетов, бытовавших среди сибирских татар. Тюркоязычный эпос, найденный на территории Челябинской области, несет традиции целого народа, вместе с тем добавляет своеобразный колорит, свойственный этносу, исторически проживающему именно в данном регионе.

Татарскими фольклористами в Челябинской области в свое время записаны и введены в научный оборот такие дастаны, как «Кузы Курпеч и Баянсылу», «Сайфульмулюк», «Йусуф китабы», «Тахир и Зухра», «Буз егет» и др., также эпические образцы фабульного характера или эпические песни из дастана.

В Центре письменного и музыкального наследия ИЯЛИ им. Г. Ибрагимова имеются магнитофонная запись [14] и текстовая расшифровка [16, п. 1, ед. хр. 19] дастана «Кузы Курпеч и Баянсылу» на средневековый сюжет, записанный Рашитом Ягфаровым от Сабиры Гайнетдиновой (1907 г. p.) в селе Кунашак Челябинской области. Еще один вариант этого же дастана с названием «Кузы Курпас и Майсылу» [16, п. 1, ед. хр. 33] записан Асией Садыковой в Троицке от Фаизы Губайдуллиной. «Кузы Курпеч и Баянсылу»- широкораспространенный среди татар эпос. На сегодняшний день известно более двадцати татароязычных вариантов данного произведения. Впервые дастан был записан в 70-е гг XIX в. у сибирских (барабинских) татар академиком В. В. Радловым [6]. В издательствах Казани на основе ранее распространенных рукописей дастан издавался в 1878, 1890, 1896, 1909 большими тиражами. Татарская версия имеет много общего 
с алтайской, уйгурской, телеутской, казахской и, в особенности, - башкирской версиями. Челябинские варианты дастана дают возможность выяснить наиболее существенные особенности содержания и формы татарской версии, довольно хорошо изученного у других тюркских народов.

«Сайфульмулюк»- дастан, занимающий важное место в плане многовариантности, активного распространения и популярности в народе. Сюжет данного произведения своими корнями восходит к известным восточным новеллам, в частности, - к «Тысяче и одной ночи». Имеется авторское произведение под названием «Сайфульмулюк» [4], написанное в начале XVI в. тюркским поэтом Маджлиси. Вариант Маджлиси тесно связан с фольклором, но претендует к литературному творчеству. Арабоязычные, персоязычные, тюркоязычные письменные источники дали импульс возникновению и широкому распространению фольклорных вариантов дастана «Сайфульмулюк». Дастан бытовал как в устном, так и в рукописном видах. В Центре письменного и музыкального наследия ИЯЛИ им. Г. Ибрагимова хранится более десяти рукописных текстов дастана. В начале XIX в. литературные произведения на татарском языке обретают форму книги, т. е. начинают активно издаваться. У истоков формирования печатной книги у татар стоит именно данное произведение. На основе рукописных списков в 1807 г. в Казани впервые за всю историю тюркского мира издается книга «Сайфульмулюк» [7]. Изданные в 1807, 1838, 1840, 1841, 1849, 1858, 1864, 1880, 1883,1888, 1895, 1898, 1902,1903, 1909 гг. в разных типографиях («Гимназия», «Университет», «Коковина», «Чирковой») варианты имеют много общего с тюркоязычной версией Маджлиси, друг от друга их отличают лишь полнота текста, стиль и лексика. Есть полное основание считать не только изустно записанные, но и изданные тексты дастана стадиально поздними фольклорными вариантами. Автор в них не указан, объем колеблется от 32 до 125 страниц [8], есть полностью поэтические, прозаические и смешанные варианты.

Для академического издания на татарском языке «Татарское народное творчество. Дастаны» был отобран вариант дастана, записанный Флорой Ахметовой в деревне Петрякс Пильнинского района Нижегородской области у информанта Лейли Алимовой (1924 г. р.) [9]. В сборник «Татарский эпос. Дастаны» на татарском языке также вошел этот вариант [10]. Не менее интересен и значителен в идейносюжетном плане вариант дастана, записанный в 1979 г. Асией Садыковой [16, п. 1, ед. хр. 21] во время фольклорной экспедиции в г. Троицк Челябинской области у Фаизы Губайдуллиной (1877 г. p.). В сюжете дастана имеются дополнительные образы, имена персонажей немного отличаются от варианта Ф. Вагаповой, заметны морфологосинтаксические особенности.

По своей популярности сюжет «Йусуф и Зулейха» занимает первое место в татарском эпосе. Татары, исповедующие ислам, с этим сюжетом были знакомы издревле, так как он упоминается в Священном Писании мусульман - Коране. В этом смысле особо стоит упомянуть произведение поэта периода Волжской Булгарии Кул Гали «Кыссаи Йусуф», широко распространенную в Волго-Уральском регионе. О большой популярности данной поэмы среди татар говорит хотя бы тот факт, что количество найденных списков рукописей на территориях между Волгой и Уралом приближается к 200 [17, с. 19]. Известно значительное влияние данного произведения XIII в. на татарский фольклор и литературу начиная с XIII - XVI вв. по сегодняшний день. Поэма Кул Гали, созданная на основе богатых исламских традиций, дала толчок к популяризации сюжета в фольклоре и распространению новых народных вариантов [11-13]. Фольклорные варианты на сюжет «Йусуф и Зулейха» имеют названия «Йосыф китабы» («Книга о Йусуфе») или «Йосыф». Рукописные варианты дастана с 1841 г. по 1915 г. в Казани издавались более 80 раз [3]. Фольклорных устных и письменных вариантов же настолько много, что невозможно их всех перечислить. В народе имело особое распространение напевное чтение дастана и своеобразный прозаический пересказ сюжета с включениями эпических песен.

Среди многочисленных фольклорных списков дастана три варианта записаны в Челябинской области. В 70-ые гг. ХХ столетия в Кунашакском районном центре Рашит Ягфаров у Сабиры Гайнутдиновой [14, касс. 2] (1907 г.р.), в г. Троицке Асия Садыкова у Фаизы Губайдуллиной [16, п. 1, ед. хр. 21a] (1877 г. p.) записали дастаны «Йосыф», в 2016 г. в Нязепетровсом районе Челябинской области в д. Арасланово у Гульнур Рахматуллиной (1953 г. р.) Лилией Мухаметзяновой записан еще один вариант дастана фабульного характера с элементами эпической песни[18]. Найденные во время экспедиций данные варианты дастана на известный сюжет отличаются 
полнотой объема и наличием музыкального декламирования эпических песен.

Кроме названных сюжетов Челябинская область также богата материалами, посвященными эпосу о Тахире и Зухре. «Тахир и Зухра»-сказание, чрезвычайно популярное на Востоке и занимающие одно из важных мест как в литературе, так и в фольклоре. Среди известных узбекских, уйгурских, балкарских, азербайджанских, турецких, казахских, туркменских, башкирских версий значительное место занимает и татарская версия. На сегодня известны свыше десяти татарских вариантов дастана. Во время экспедиции в Кунашакский район Челябинской области Рашит Ягфаров у Сабиры Гайнутдиновой (1907 г.р.) записал один вариант дастана «Тахир и Зухра» $[16$, п. 1, ед. хр. 21]. В то время информант Сабира Гайнутдинова спросила у фольклориста Р. Ягфарова: «Как передать содержание? Рассказать как в книге, или передать коротко?» («Китаптагыча сөйлимме? Кыскача сөйлимме?») [9, с. 370]. В архиве ИЯЛИ им. Г. Ибрагимова хранится вариант Фаизи Губайдуллиной, записанный в 1978 г. в г. Троицк Асией Садыковой [18]. Из общих мотивов в этих вариантах встречаются мотив бездетности, помолвка еще не родившихся детей; образы святого старца-дервиша, араба, старушкиколдуньи; эпизоды деления яблока, выход на природу (сахрага чыгу), учеба в школе, причитания по поводу разлуки, смерть молодых влюбленных и т. д. Особо следует подчеркнуть сохранение в варианте Сабиры Гайнутдиновой эпизодов причитаний, повторов, стихотворных диалогов; это - особенности устного исполнения дастана. Общность основного сюжета, интерпретация мотивов, переплетенность поступков героев с поступками в других вариантах ставит эти варианты в один типологический ряд с другими татарскими дастанами о Тахире и Зухре.

«Буз егет»-фольклорное произведение, распространенное среди татар, башкир, ногайцев, казахов, кумыков, балкарцев и др. тюркских народов. «Буз егет» бытовал и в устной, и письменной формах, в период книгопечатания издавался в виде книг. В татарской фольклористике самыми полными считаются варианты Бахави и Курмаши. Рашит Ягфаров в 1978 г. в селе Узбагаряк Кунашакского района Челябинской области записал вариант дастана «Буз егет» у информанта Нагимы Мустакимовой (1906 г. р.) [14, касс. 2.], расшифровал текст дастана [15, п. 2, ед. хр. 19-22]. Данный вариант представляет из себя прозаический текст с поэтической вставкой, состоящей из двадцати строк, разделенных на пять рифмованных строф.

Bce вышеназванные списки дастанов с магнитофонными записями хранятся в фондах Центра письменного и музыкального наследия ИЯЛИ им. Г.Ибрагимова, некоторые из дастанов имеют нотные образцы. Все имеющиеся варианты эпических произведений нашли свое достойное место в академических изданиях «Татар халык ижаты» («Татарское народное творчество») либо полностью, либо указаны как варианты того или иного дастана. Все эпические произведения, записанные в Челябинской области у татароязычных информантов татарскими фольклористами во время экспедиционных выездов, введены в научный оборот, а часть текстов издана.

ИЯЛИ им. Г. Ибрагимова, как единственный научно-исследовательский центр всестороннего изучения языка татарского народа, его этнических традиций, этнолитературы, устного народного творчества, рукописного наследия, народной музыки, эпитафики и пр., стремится со всей ответственностью выполнять взятые на себя обязательства. В последнее десятилетие экспедиционная деятельность ИЯЛИ им. Г. Ибрагимова стала заметно активней и насыщенной. Если в предыдущие годы работа велась по отдельным специальностям, то в настоящее время экспедиции в регионы компактного проживания татар проводятся в комплексном порядке, т. е. в них участвуют фольклористы, диалектологи, археографы, музыковеды и др. Задача экспедиционных выездов состоит не только в сборе материалов и передаче их в архив, но и в большей степени - в анализе, описании, введении в научный оборот и ознакомлении с культурным наследием широкого круга читателей. Именно поэтому с 2010 г. в Институте налажен выпуск научно-популярных серий «Из сокровищницы научных экспедиций». К сегодняшнему дню изданы всего 15 книг из данной серии по результатам экспедиций в разные регионы России и районы Республики Татарстан, готовится к изданию книга по Челябинской области [5].

Серия представляет собой новаторскую, единственную по своему охвату документальную публикацию произведений фольклора, материалов археографии, диалектологии по всем этническим группам татар на языке оригинала. Наряду с вновь найденными образцами, серия предполагает также публикацию найденных во время экспедиций прошлых лет 
образцов фольклора, доселе не изданных и ждущих своей очереди в архивах. С рукописями неизданных текстов или музыкальными документами можно ознакомиьтся в Центре письменного и музыкального наследия ИЯЛИ им. Г. Ибрагимова.

Ниже представляем нотные тексты некоторых дастанов, записанные в Челябинской области учеными-фольклористами в 70-х гг. прошлого столетия у вышеназванных информантов. Образцы нот дастанов «Кузы Курпеч и Баянсылу», «Сайфульмулюк», «Йусуф», «Тахир и Зухра» (в двух вариантах), «Буз егет»немаловажный источник для этномузыковедов и эпосоведов в изучении духовного наследия народа. Эпические памятники, исполненные сказителями Южного Урала - образцы не только национального эпоса, они важны и как общечеловеческие нематериальные ценности и служат ценными источниками для углубленного изучения проблемы истории татар и башкир в сравнительном аспекте и в контексте Евразийской цивилизации.

Итак, территориальная, географическая разобщенность татар способствовала историческому формированию и развитию у разных этнических групп, компактно проживающих на разных территориях, тех или иных культурных ценностей. Этот многовековой процесс хорошо прослеживается на примере распространения эпоса в Южном Урале. Сравнительная активность у сибирских татар, также и у башкир искусства сказительства повлияла на сохранение у татар «живого» эпоса. Традиции устного декламирования эпического текста, характерная алтайцам, якутам, тывинцам, шорцам, хакасам, башкирам, проживающим на бескрайних сибирских просторах или соседствующим с народами Сибири, наблюдается и в эпическом творчестве татар, веками проживающих в Челябинской области Российской Федерации. Найденные здесь во время экспедиций варианты дастанов «Кузы Курпеч и Баянсылу», «Сайфульмулюк», «Йусуф китабы», «Тахир и Зухра», «Буз егет»-эхо определенной части общетюркских эпических традиций, отражающее результаты взаимосвязей разных народов и культур.

\section{СӘИФЕЛМӨЛЕК}
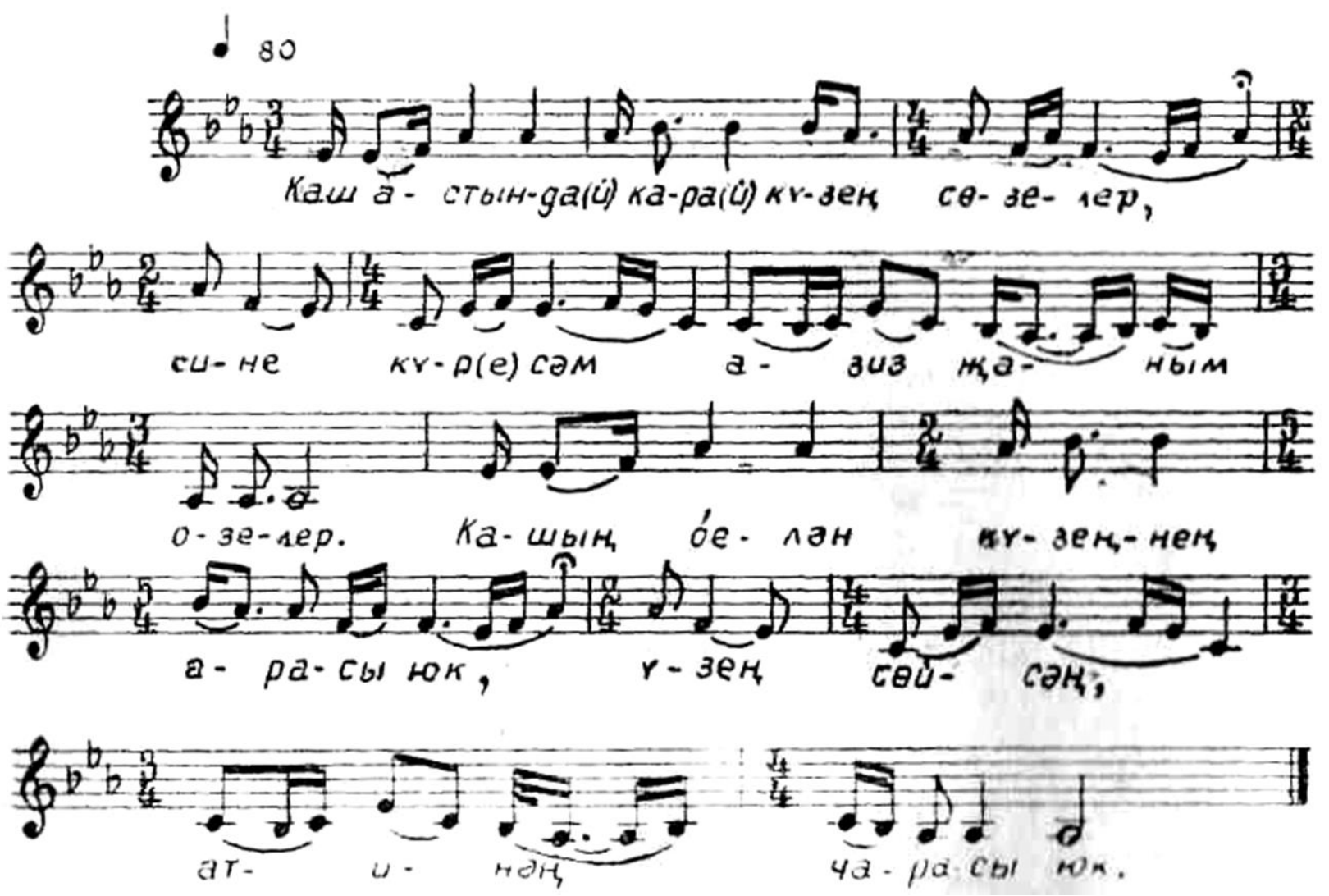


\section{ИОСЫФ КИТАБЫ}

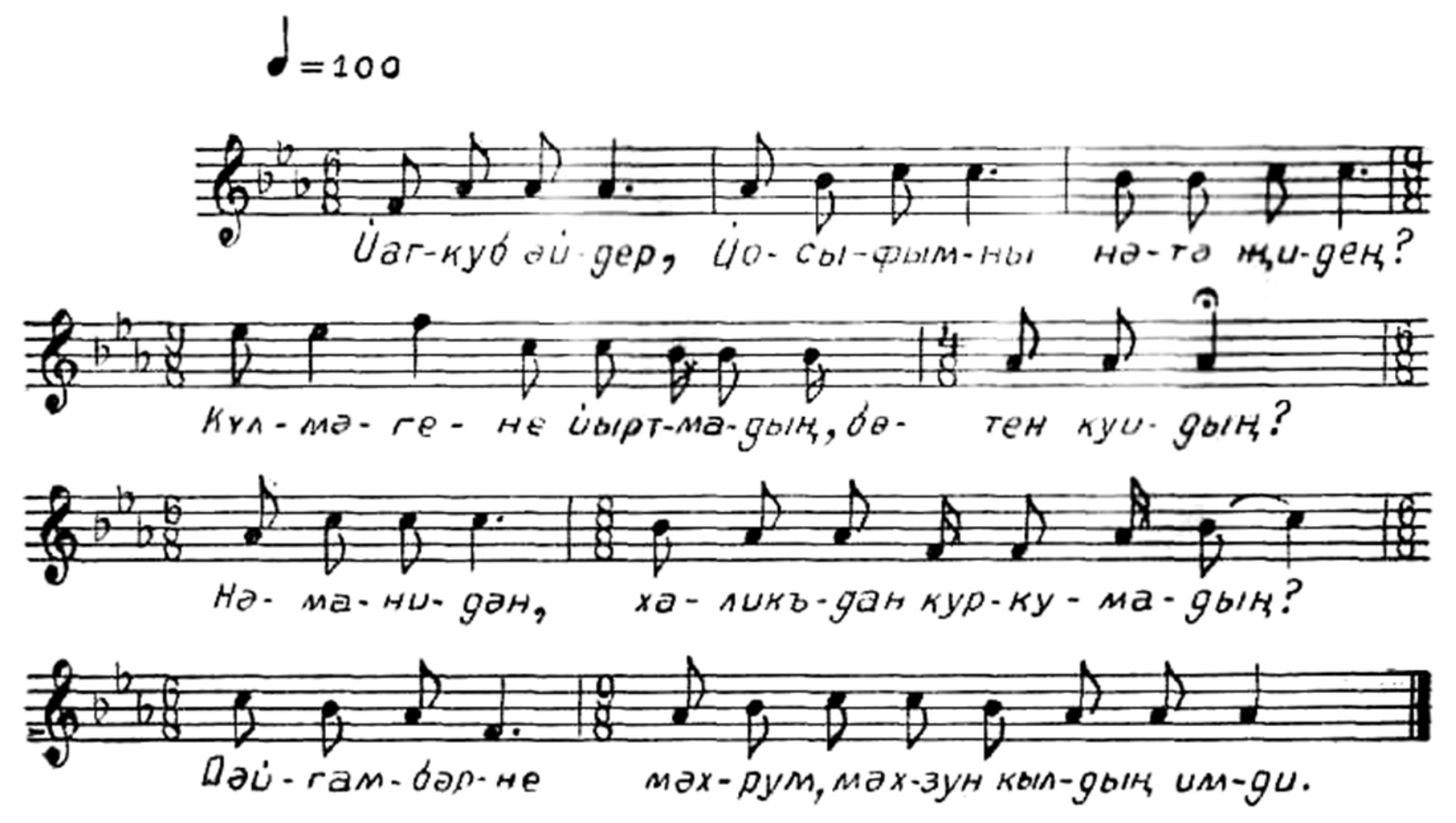

ИОСЫФ Вә ЗөЛәИХА
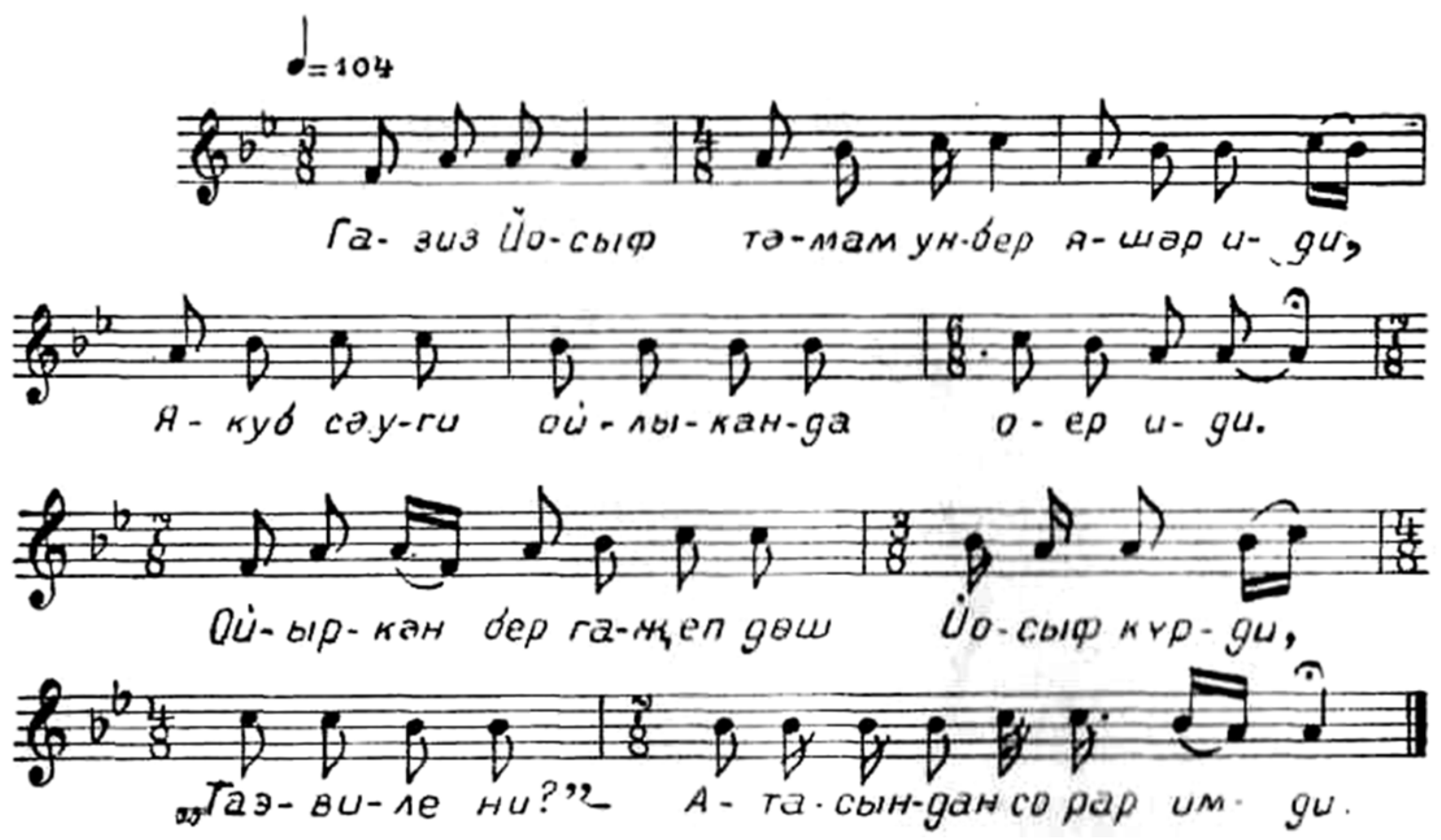


\section{кУЗЫ көРПә}

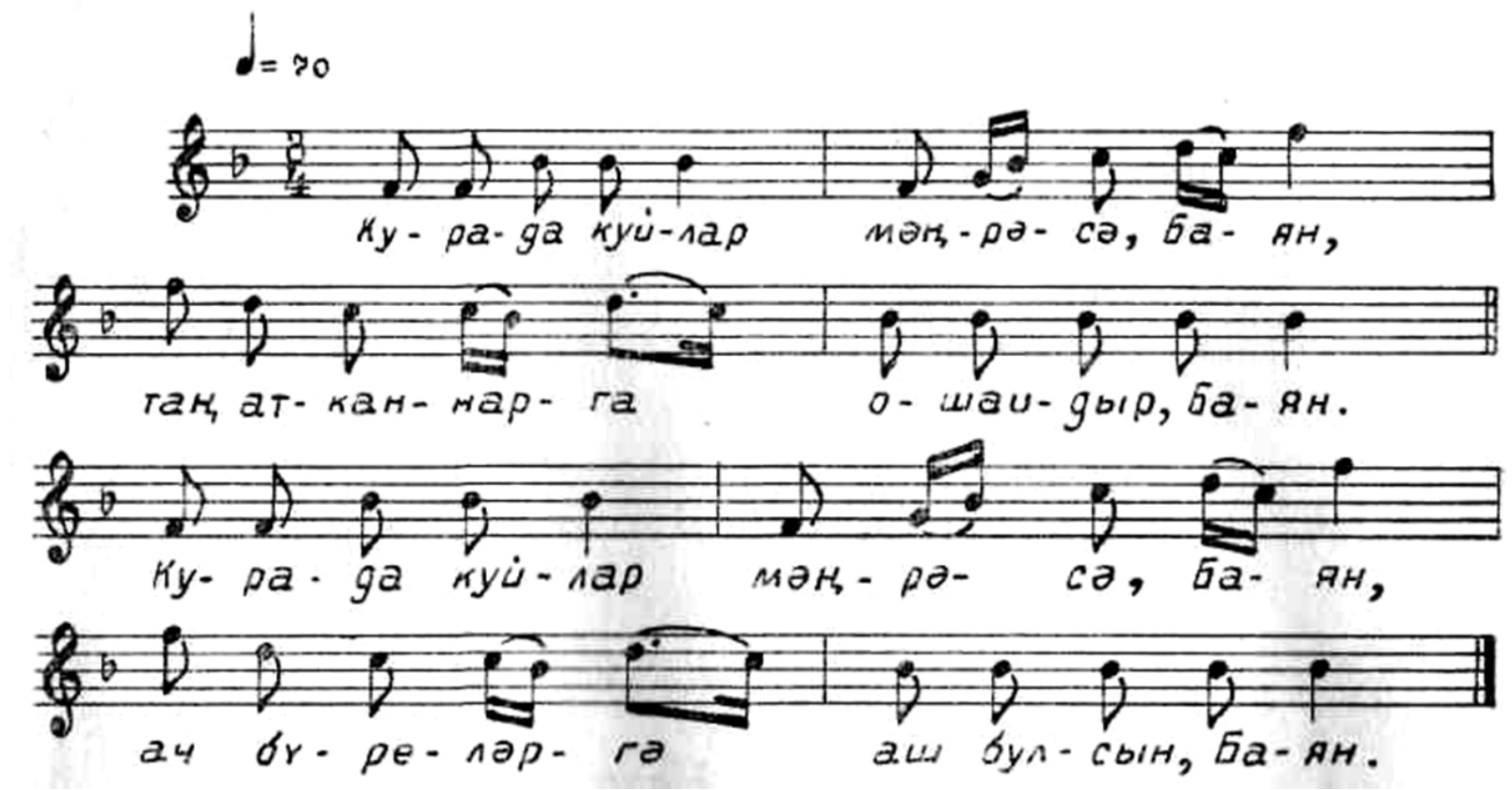

\section{ТАһИР ЖЫРЫ}

$J=100$

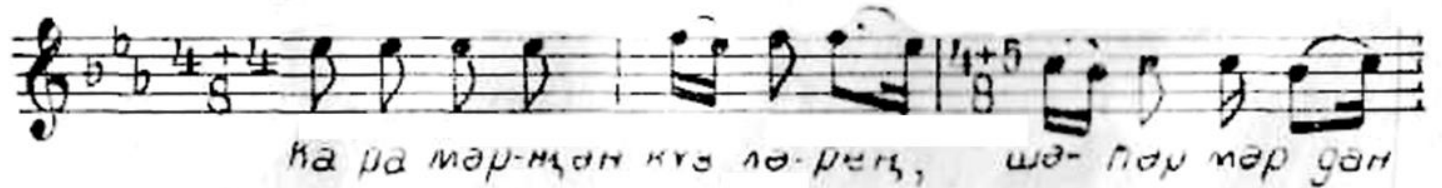

और

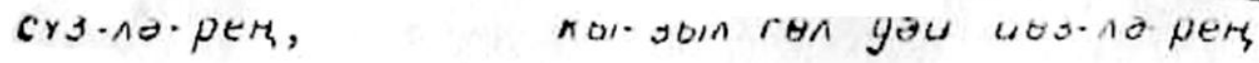
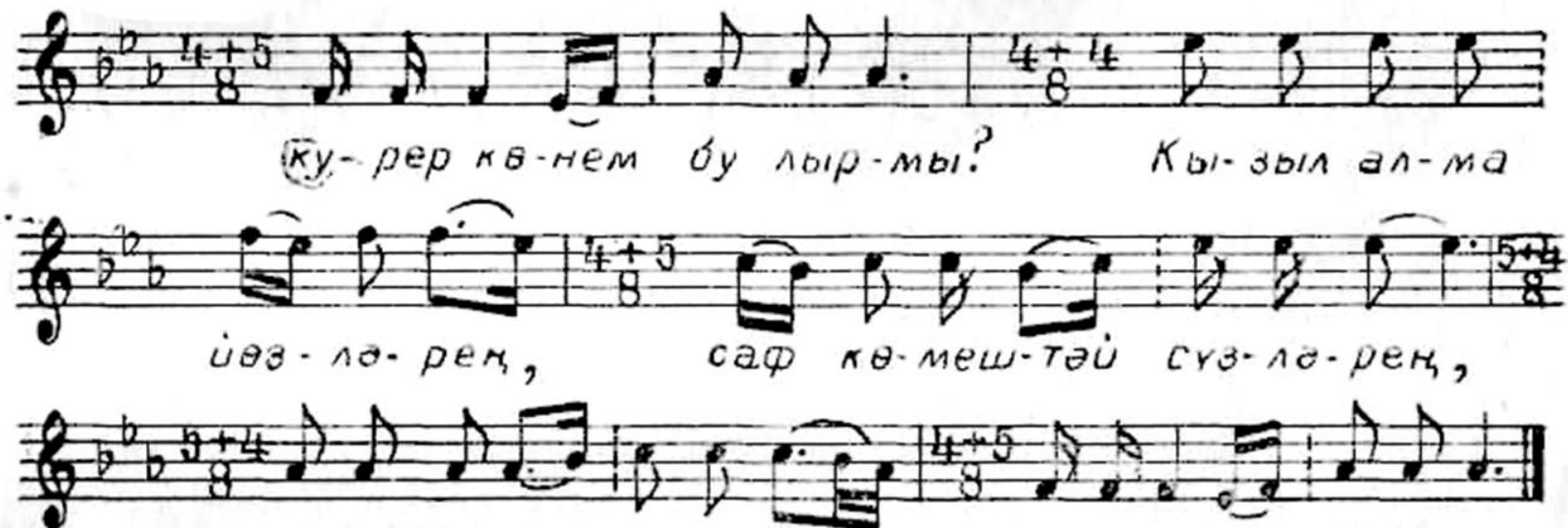

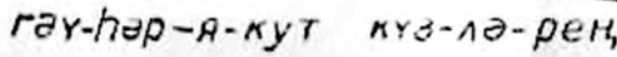
кr-pep кө-нем бy-nolp-mol? 


\section{БYЗ ЕГЕT}
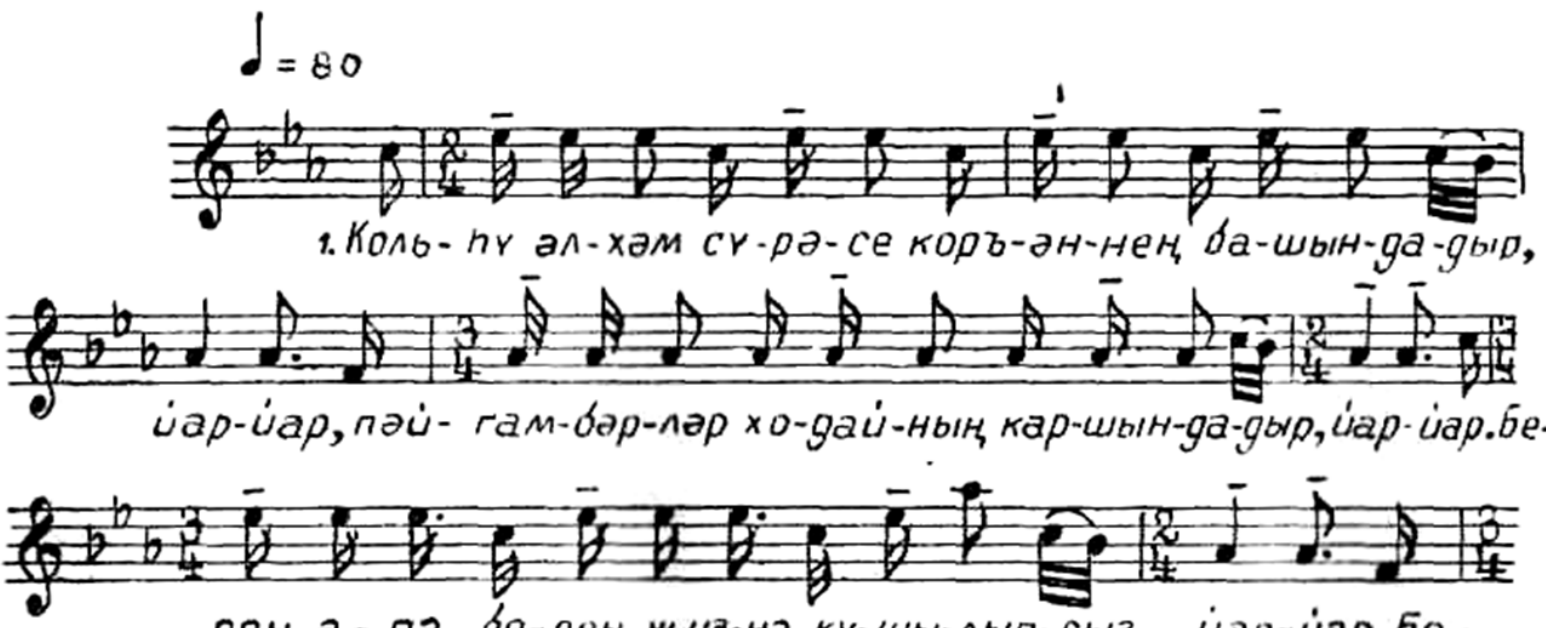

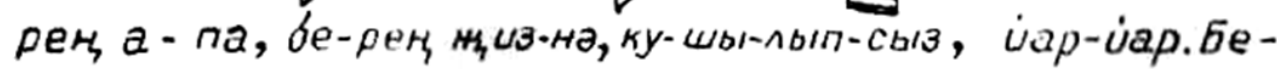

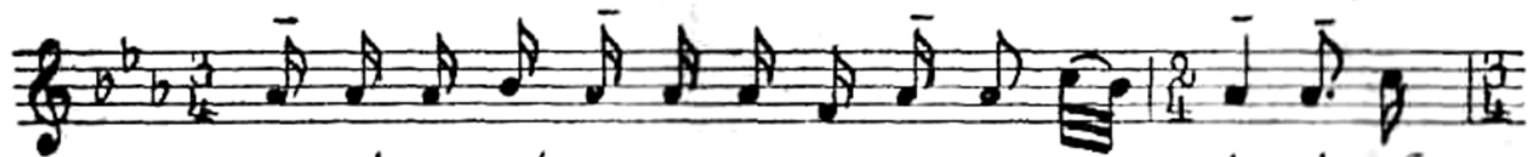

рең аиं-golp, бе-реккөн-gep, ку-шы-лып-сыз, сіар-іар. бе-
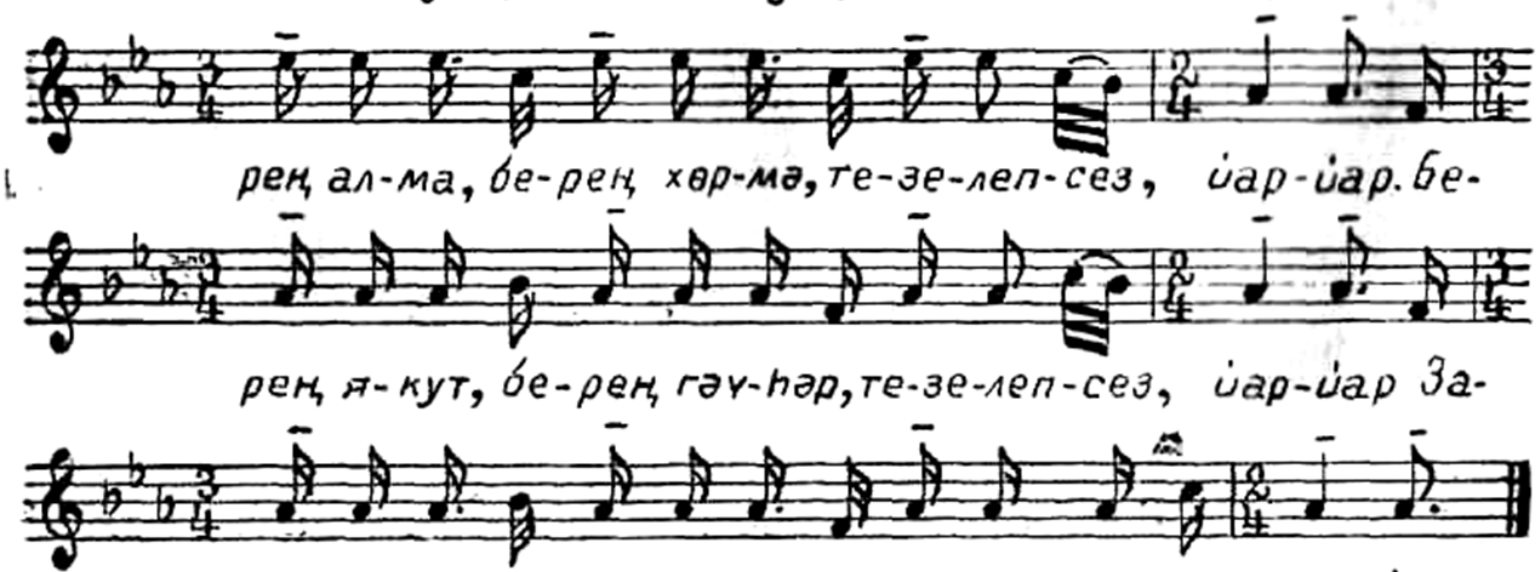

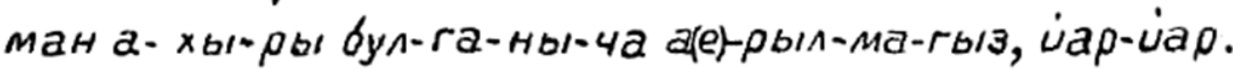

Список литературы и источников

1. Исхаков Д. М., Измайлов И. Л. Этнополитическая история татар в VI - первой четверти XV века. Казань, 2000. 136 с.

2. Долгих Б. О. Родовой и племенной состав народов Сибири в XVII веке. Москва, 1960. 624 с.

3. Каримуллин А. Г. Татарский фольклор. Аннотированный указатель литературы. 1612-1981. Казань, 1993. Ч. 1. 136 с.

4. Мәжлиси. Сәйфелмөлек: дастан. Казань, 2007. 374 б.

5. Милли-мәдәни мирасыбыз: Чиләбе өлкәсе татарлары. Казан, 2018. 432 б. (Из сокровищницы научных экспедиций, кн. 16).

6. Радлов В. В. Образцы народной литературы тюркских племен, живущих в Южной Сибири и Дзунгарской степи. Ч. IV: Наречия барабинцев, тарских, тобольских и тюменских татар. Казань, 2012.519 c.

7. Сәйфелмөлек. Казан, 1807. 124 б.
8. Сәйфелмөлек китабы. Казан, 1807. 115 б.

9. Татар халык ижаты. Дастаннар. Казан, 1984. C. $151-158$.

10. Татар эпосы. Дастаннар. Казан, 2004. C. $110-118$.

11. Хисамов Н. «Кыйссаи Йосыф» поэмасының халык поэзиясенә тәэсире // Урта гасыр татар әдәбияты тарихыннан. Казан, 1981. Б. 23-37.

12. Хисамов Н. «Кыйссаи Йосыф» поэмасының халыкта яшәеше // Казан утлары. 1974. № 9. Б. 175182.

13. Хисамов Н. Бөек язмышлы әсәр. Казан. 1984. 334 б.

14. Центр письменного и музыкального наследия Института языка, литературы и искусства им. Г. Ибрагимова Академии наук Республики Татарстан (ЦПиМН ИЯЛИ им. Г. Ибрагимова АН РТ). Фольклорный фонд. 1979. Колл. 93. П. 1. Ед. хр. 21. Кассеты 1, 2. 
15. ЦПиМН ИЯЛИ им. Г. Ибрагимова АН РТ. Фольклорный фонд. Колл. 90. П. 1. Ед. хр. 1-2, 1965. П. 2, Ед. хр. 19-22.

16. ЦПиМН ИЯЛИ им. Г. Ибрагимова АН РТ. Фольклорный фонд. Колл. 91. П. 1. Ед. хр. 1-15, 1618, 18-21, 21a, 30-35, 36-37, 38. П. 2. Ед. хр. 19-65.
17. Хисамов Н. Ш. Поэма «Кысса-и Йусуф» Кул 'Али: анализ источников сюжета и авторского творчества. Москва, 1979. 251 с.

18. ЦПиМН ИЯЛИ им. Г. Ибрагимова АН РТ. Фольклорный фонд. 2016. П 5. Колл. 93. П. 1. Ед. хр. 21.

Lilia Kh. Mukhametzianova, Dr. of Philosophical Sciences, Associate Professor Galimdzhan Ibragimov Institute of Language, Literature, and Art of the Academy of Science of the Republic of Tatarstan (Kazan, Russia) lilmuhat@mail.ru

\section{BETWEEN VOLGA AND URAL: EPIC VALUES OF TARTARS AND BASHKIRS IN CHELYABINKAYA OBLAST OF THE RUSSIAN FEDERATION}

Abstract. The paper reviews the most popular plots of dastans, epic opus of Tartar and Baskir peoples' creativity, analyses some peculiarities of plots of known dastans. The author notes a relation between migration of a part of Bashkirs and Tartars in Siberia and genre changes in dastans. Fragments of musical notation of several dastans are given. Also, the key directions of work of Galimdzhan Ibragimov Institute of Language, Literature, and Art of the Academy of Science of the Republic of Tatarstan (Kazan, Russia) in search, scientific analysis and popularization of samples of a dastan are outlined.

Keywords: folklore of Turkic peoples of Russia, Tartar folklore, Bashkir folklore, Tartar epos, Bashkir epos, dastan (epos), plot of a dastan, ethnographic company, Galimdzhan Ibragimov Institute of Language, Literature, and Art of the Academy of Science of the Republic of Tatarstan.

\section{References}

1. Iskhakov, D. M. Etnopoliticheskaya istoriya tatar v VI - pervoj chetverti XV veka [Ethnic and Politic History of Tartars in $6^{\text {th }}$ Century - the First Quarter of the $15^{\text {th }}$ Century] / D. M. Iskhakov, I. L. Izmajlov. Kazan, 2000. 136 p. [In Russ.].

2. Dolgih, B. O. Rodovoj i plemennoj sostav narodov Sibiri v XVII veke [Tribal Composition of Peoples in Siberia in $17^{\text {th }}$ Century]. Moscow, 1960. 624 p. [In Russ.].

3. Karimullin, A. G. Tatarskij fol'klor. Annotirovannyj ukazatel' literatury. 1612-1981 [Tartar Folklore. Annotated Reference. 1612-1981]. Kazan, 1993. Pt. 1. 136 p. [In Russ.].

4. Mәжlisi. Səjfelmølek: dastan [Majlis. Leaf Fall: Dastan]. Kazan, 2007. 374 p. [In Tat.].

5. Milli-mədəni mirasybyz: Chiləbe elkəse tatarlary [Our Ethnic and Cultural Heritage: Tatars in Chelyabinsk Oblast]. Kazan, 2018. 432 p. (From the Treasure of Research Expeditions. Book 16). [In Tat.].

6. Radlov, $V . V$. Obrazcy narodnoj literatury tyurkskih plemen, zhivushchih v Yuzhnoj Sibiri i Dzungarskoj stepi. Ch. 4: Narechiya barabincev, tarskih, tobol'skih i tyumenskih tatar [Samples of Folk Literature of Turkic Peoples live in South Siberia and Junggar Steppe. Pt. 4. Dialects of Barabins, Tarsk, Tobol, Tumen Tartar]. Kazan, 2012. 519 p. [In Russ.].

7. Sojfelmelek [Leaf Fall]. Kazan, 1807. 124 p. [In Tat.].

8. Sojfelmelek kitaby [Book Leaf Fall]. Kazan, 1807. 115 p. [In Tat.].

9. Tatar halyk іжаty. Dastannar [Tartar Folklore. Eposes]. Kazan, 1984. Pp. 151-158. [In Tat.].

10. Tatar eposy. Dastannar [Tartar Eposes. Das- tans]. Kazan, 2004. Pp. 110-118. [In Tat.].

11. Hisamov, N. «Kyjssai Josyf» poemasynyң halyk poeziyasenə təesire [Influence of Poem "Tale about Yusuph" on Traditional Poerty] // Urta gasyr tatar ədəbiyaty tarihynnan [History of Tartar Literature of the Middle Ages]. Kazan, 1981. Pp. 23-37. [In Tat.].

12. Hisamov, N. «Kyjssai Josyf» poemasyny halykta yashəeshe ["Tale about Yusuph": Life of a People's Poem]// Kazan utlary [Lights of Kazan]. 1974. No. 9. Pp. 175-182. [In Tat.].

13. Hisamov, N. Beek yazmyshly osər [Great Destity]. Kazan. 1984. 334 p. [In Tat.].

14. Galimdzhan Ibragimov Institute of Language, Literature, and Art of the Academy of Science of the Republic of Tatarstan, Center of Written and Musical Heritage. Folklore Collection. 1979. Cassettes 1, 2. Coll. 93. Case 1. Ex. 21. Cassette 1. [In Russ./Tat.].

15. Galimdzhan Ibragimov Institute of Language, Literature, and Art of the Academy of Science of the Republic of Tatarstan, Center of Written and Musical Heritage. Folklore Collection. Coll. 90. Case 1. Items. 1-2, 19-65. Case 2, Items 19.

16. Galimdzhan Ibragimov Institute of Language, Literature, and Art of the Academy of Science of the Republic of Tatarstan, Center of Written and Musical Heritage. Folklore Collection. Coll. 91. Case 1. Items 1-15, 16-18, 18-21, 21a, 30-35, 36-37, 38. Case 2. Items 19-65. Folklore Collection. 2016. Case 5. Coll. 93. Case 1. Items 21 и др. [In Russ./Tat.].

17. Hisamov, N. Sh. Poema «Kyssa-i Jusuf» Kul 'Ali: Analiz istochnikov syuzheta i avtorskogo tvorchestva [Qol Ghali's Poem "Tale about Yusuph": Analysis of Sourses for Plot and the Writer's Work]. Moscow, 1979. 251 p. [In Russ.]. 